\title{
Synopsis on Non-invasive Ventilation in Neonatology
}

\author{
Akshay Mehta DCH DNB ${ }^{1 *}$, Bhawna Malik MBBS MD ${ }^{2}$, Zoe Smith MBBS, MSc, FRCPCH \\ ${ }^{1}$ Department of Paediatric Cardiology Southampton General Hospital, Southampton, United Kingdom. \\ ${ }^{2}$ Department of Paediatric Intensive Care King's College and Hospital, London United Kingdom. \\ ${ }^{3}$ Neonatal Consultant, Neonatal Intensive Care Unit, Great Ormond Street Hospital, London United Kingdom.
}

*Corresponding author: Akshay Mehta, Department of Paediatric Cardiology Southampton General Hospital, Southampton, United Kingdom. Received date: March 05, 2021; Accepted date: June 28, 2021; Published date: July $02,2021$.

Citation: A Mehta, B Malik, Z Smith. (2021) Synopsis on Non-invasive Ventilation in Neonatology. International Journal of Clinical Case Reports and Reviews. 7(4); DOI: 10.31579/2690-4861/128

Copyright: (C) 2021 Akshay Mehta, This is an open-access article distributed under the terms of the Creative Commons Attribution License, which permits unrestricted use, distribution, and reproduction in any medium, provided the original author and source are credited.

\begin{abstract}
Non-invasive ventilation (NIV) is a mode of respiratory support commonly used on the neonatal unit. Since the advent of NIV, it has evolved from be- ing used as a mode of respiratory support to wean infants from mechanical ventilation (MV) to a primary mode of respiratory support. NIV improve the functional residual capacity in the newborn (at term or preterm) avoiding invasive actions such as tracheal intubation. Newer methods of NIV support such as nasal bilevel positive airway pressure (BiPAP) and humidified high flow nasal cannula oxygen therapy (HHFNC) have emerged in attempts to reduce intubation rates and subsequent MV in preterm infants. With this synopsis, we aim to discuss various available NIV modes of ventilation in Neonatology, including indications, physiological principle, practical as- pects and effects on important short and long term morbidities associated with the use of NIV.
\end{abstract}

Keywords: heated humidified high flow nasal cannula, nasal continuous positive airway pressure, nasal intermittent positive pressure ventilation, noninvasive ventilation, preterm infants

\section{Introduction}

Invasive Mechanical Ventilation (IMV) has been the primary treatment in Respiratory distress Syndrome (RDS) for Very low birth weight babies (VLBW). Although lifesaving, IMV is an important risk factor in developingBroncho pulmonary dysplasia (BPD) and its related complications [1].

Affected infants require comprehensive medical followup and treatment af-ter hospital discharge with frequent hospital readmissions, home based oxygen therapy, treatment for pulmonary hypertension, these factors thus significantly affect quality of life of affected infants [2].

Despite advances in neonatal medicine, such as improved antenatal care, antenatal corticosteroids and surfactant administration; there hasn't been significant fall in incidence of BPD in last decade [3].

IMV causes volutrauma, barotrauma, inflammatory mediated alveolar and vascular destruction resulting in progressive impaired gas exchange. To al-leviate the harmful effects of IMV on the premature lungs, nasal CPAP was introduced as a non-invasive ventilation strategy. CPAP was first used clini-cally in 1971, CPAP significantly reduced the need for IMV, but failure rates of almost $50 \%$ have prompted for seeking more effective NIV modalities [4, 5].

There are various non-invasive ways in which respiratory support can be provided to neonates with parenchymal lung disease or apnoea viz heatedhumidified high flow nasal cannula (HHHFNC), Continuous Positive Airway Pressure (CPAP), Nasal Intermittent Positive Pressure Ventilation (NIPPV).

\section{Heated Humidified High Flow Nasal Cannula (HHHFNC)}

HHHFNC is commonly used in most NICUs throughout the world. It is a flow based non-invasive respiratory support which delivers heated and humidi-fied gas.

Oxygen delivered by "low flow" nasal cannula (LFNC) typically refers to theuse of flow rates of less than or equal to $1-2 \mathrm{~L} /$ minute. Usually the gas usedis unblended (i.e.100\% oxygen), unheated and non-humidified. LFNC is used commonly in growing convalescent preterm infants (often with chron-ic lung disease). In contrast, "high flow" nasal cannula (HFNC) has been used to refer to the administration of oxygen or blended oxygen/air to newborn infants via nasal cannula at higher flow rates than LFNC. The useof devices providing use of humidified high flow by nasal cannula (HFNC) to these babies has increased dramatically over last few years due to rela-tive simplicity of its use and user friendly nature [6]. Most commonly it is used for babies recovering from RDS on low pressure nCPAP and FiO2 andwho would traditionally undergo a period of cycling nCPAP regimen before discontinuing respiratory support. Anecdotally, HFNC allows infant to be handled less, makes easier to receive kangaroo care and breast feeding than nCPAP. The clinical role of HFNC is still evolving and further controlled clinical trials are needed to identify which infants benefit most from HFNC.Despite its 
popularity, the use of HFNC should not be extended as a routine replacement for nCPAP until further large randomised controlled trialscomparing efficacy and safety are published and the unit gains enough ex-perience using it on stable babies [7].

\section{Physiological Principles of HFNC (8)}

1. Washout of Naso-pharangeal dead space

2. Reduces respiratory resistance and hence decreases work of breathing

3. Provides continuous distending pressure; pharyngeal pressure providedis directly related to flow but inversely related to infant size.

4. Respiratory gas conditioning; improves lung and airway mechanics byeliminating the effect of drying/cooling.

\section{Differences from nCPAP}

HFNC should not be regarded as a form of nCPAP. Rather, it is a distinct respiratory support modality that should be assessed on its own merits in the same way as for other modalities of ventilation.

nCPAP has been shown to reduce extubation failure, treat apnoea and res-piratory distress syndrome, and may reduce chronic lung disease by min- imising duration of mechanical ventilation. Oxygen administered by nCPAPis usually blended, humidified and heated. Contrary to HFNC, the pressuredelivered by the circuit for nCPAP is measured and regulated directly. Theuse of binasal prongs to deliver nCPAP can be associated with trauma to the nasal septum and distortion of the nares. Difficulties with successful ap-plication of nCPAP are principally related to the bulky interface with the pa-tient leading to problems maintaining proper position and effectiveness. It also is less patient friendly making handling and feeding more difficult while on nCPAP [9].

In contrast, HFNC provides blended, heated, humidified oxygen at flow rates higher than the patient's inspiratory flow rate thereby reducing work of breathing and ensuring that intended oxygen concentration is delivered.If prongs are selected properly, HFNC is an open system potentially reduc-ing the risk of baro/volutrauma and reducing nasal mucosal damage. It cre-ates a flow related variable distending pressure delivered to the neonates upper airway and lungs that unlike CPAP is unmeasurable in clinical prac-tice,. Adult studies suggest it provides low PEEP, improves mucosal perfu-sion and stimulates respiratory drive. The interface is less bulky, allowing easy access for parents and nurses for handling and feeding purposes. $[10,11]$

\section{Possible Risks}

Concerns that have been expressed include increased risk of infection (Vapotherm only), excessive airway pressure generation (avoid a tight fit nasal prong) and local trauma (avoid a tight fit nasal prong)

\section{Indications for use}

No formal recommendations are available for specific clinical indications published. Collectively published studies suggest a wide potential role for HFNC in respiratory care of the neonate.

Consider HFNC on:

- Stable babies recovering from RDS or with chronic lung disease

- $\mathrm{FiO}_{2} \leq 30 \%$

- $\quad$ Ready to be cycled off on nCPAP at a pressure of $5 \mathrm{~cm} \mathrm{H} 20$ or lower.

- No significant apnoea, desaturations or bradycardia requiring frequent stimulation. These set of babies are likely to benefit from HFNC as weaning will be more physiological, and user friendly.

Relative Contraindications:

- $\quad$ Should not be used on babies where a suitable loose fit nasal cannulais not available (extremely small nares). Avoid tight fit nasal cannula at all cost

- Use judgment for babies with significant CLD. This may take some ex- perience

- $\quad$ Not to be considered for babies who can be taken off nCPAP to air di-rectly i.e. stable term/ near term babies.

\begin{tabular}{|c|c|}
\hline Variables & Suggested Initial Parameters \\
\hline Adequate gas heating & Maintain at 34-37 o C \\
\hline Adequate gas humidification & $100 \%$ Relative humidity \\
\hline Allowance for gas leak from nares & Preferred cannula to nares ratio $\sim 0.50$ \\
\hline Maximum allowed flow $=81 \mathrm{~min}$ & Per manufacturer's design/ approval \\
\hline Wean FiO2 first & $\begin{array}{c}\text { Consensus with limited trial data Wean to }<0.30 \\
\text { before weaning flow }\end{array}$ \\
\hline Increase flow & For increasing FiO2 and/or WOB \\
\hline Initial flow rate & Begin at 4-6 1 min ${ }^{-1}$ \\
\hline Decrease flow & When stable FiO2, RR and WOB for $12-24 \mathrm{~h}$ \\
\hline Change to other NIV mode & If 2 consistently $>0.40$ \\
\hline & If consistently increased WOB If excessive or severe \\
& apnea \\
\hline Stopping nHFT & Flow 4 l min ${ }^{-1}$ \\
\hline
\end{tabular}

Table 1: Initial Settings on HFNC

\section{Nasal CPAP- Nasal Continuous Positive Airway} Pressure

CPAP aims to prevent alveolar collapse at end expiration. It is used for in-fants with moderate respiratory distress and for recurrent apnoeas. It is alsoused for weaning from mechanical ventilation. Use of early CPAP has signif- icantly reduced the need for invasive ventilation and surfactant administra-tion in preterms $[12,13]$. 


\section{Physiological principle:}

1.Provides continuous distending pressure to maintain functional residual capacity (FRC) -reduction of airway collapse by decreased airway resistance and reduces work of breathing

2. Splints the pharyngeal airway to avoid obstruction

3. Keeps the surfactant on alveolar surface and thus promotes reduction ofalveolar edema

4. Improves the ventilation-perfusion ratio and decreases intrapulmonaryshunting

\section{Indications for CPAP include (14):}

- $\quad$ Babies weighing less than 1000 grams with respiratory distress and agood respiratory drive.

- $\quad$ Clinically increasing respiratory distress in any gestation (check to ruleout pneumothorax)

\section{Use CPAP with caution in}

- Meconium aspiration syndrome, for the risk of pneumothorax in avigorous baby

- Gastrointestinal malformations for e.g. Tracheooesophageal fistula; for the risk of abdominal distension causing splinting of the chest leading to a further compromise of ventilation. In this situation insert an NG tube and aspirate the stomach periodically.

\section{Practical considerations:}

- $\quad$ The most appropriate size of hat and nasal prongs / mask should be selected.

- The fit of these should be "snug" but never tight. The fixing ties should never be over tightened in order to maintain a seal as this maycause damage to the face.

- $\quad$ Humidity must be used when delivering CPAP; humidified oxygen must be delivered at a temperature of $37 \mathrm{C}$ at the baby's nose.

- Babies with respiratory distress and who weigh less than 1000grams, requiring non-invasive respiratory support should be nursed on nC-PAP.

- $\quad$ Normal CPAP pressures are 5 to $6 \mathrm{~cm}$ of water. The use of higher lev- els of CPAP for individual babies must be agreed by the multi -disci- plinary team (MDT) and this decision documented in the notes. As the condition of the baby improves the pressures can be carefully weaned to $4 \mathrm{~cm}$ water.

- $\quad$ Some babies become agitated on CPAP. Appropriate "nesting" and removal of noxious stimuli such as light and noise can alleviate this. Occasionally sedation such as Chloral Hydrate may need to be con- sidered if these strategies are not working.

For babies extubated onto CPAP not being able to maintain an ad-equate respiratory effort, re- intubation will be required. Signs that aid in the assessment for the need to be reintubated are:

- $\quad$ Significantly increased frequency and severity of apnoeas and brady-cardias

- Increasing oxygen requirements over $60 \%$ in term babies and over $40 \%$ in preterm babies

\section{- Increased work of breathing}

- Poor gases

Complications of CPAP (15):

- Gaseous distension of the stomach +/- feeding difficulties

- Nasal trauma from the pressure of the prongs / mask

- Pneumothorax

Weaning from CPAP:

- $\quad$ Once respiratory distress is settling, weaning from CPAP may be commenced.

- $\quad$ Gradually try to wean the oxygen to air and the PEEP to 5 $\mathrm{cm}$ water.

- When the PEEP is $5 \mathrm{~cm}$ water and the oxygen requirement is $\leq 30 \%$ consider switching over to High flow nasal cannula Oxygen (HFNC) and monitor work of breathing. See HFNC guideline.

- Babies weighing less than 1000 grams, who are being nursed on nC-PAP, should not be weaned from CPAP until the MDT decide that the baby has a consistently strong respiratory drive.

- If the baby has to work excessively to maintain respiratory status thenCPAP should be reinstated. Signs of increase in work of breathing in-clude:

Tachypnoea consistently $>60 / \mathrm{min}$

Tachycardia - >160beats / min

Increasing sub and intercostal recessions

Increase in oxygen by more than $10-20 \%$

Increase in the number of desaturations/bradycardias

Removal from CPAP without Weaning:

Term/Near term babies may require CPAP for only a short time and may notneed to wean incrementally from CPAP but may cope well in ambient oxy-gen or air.

\section{Use of Blood Gases in babies on long term CPAP}

Any baby who is placed on CPAP for worsening respiratory distress shouldhave gases taken as frequently as clinical condition dictates. As a guide -

1. For Term / near term babies

- Take gases $4 \mathrm{hrs}$ after CPAP discontinued if clinical condition remains stable in between. Earlier gases are recommended if clinical condi- tion seems unstable to assess need for escalating support.

- If subsequent saturations are $>98 \%$ in air, gases do not need to be taken again.

- If in oxygen, take at least one gas daily

2. Preterm/LBW Babies 1 to 14 day old

- $\quad$ Gases should be taken at least daily for babies who are on CPAP in oxygen or on HFNC in oxygen

- $\quad$ Gases should be taken at least 2 times a week for babies on CPAP inair.

- $\quad$ Preterm/LBW Babies 14 days to 28 days

- Gases should be taken at least 2 times a week for babies who are sta-ble on CPAP in oxygen. 
- Gases should be taken once a day for babies who are

Variables

Adequate gas heating

Adequate gas humidification

Gas flow

Initial CPAP pressures

Wean $\mathrm{FiO}_{2}$ first

Change to other NIV mode on HFNC inoxygen and on alternate days in those who are on HFNC in air.

\section{Suggested Initial Parameters}

Maintain at 34-37 C

$100 \%$ Relative humidity

8-12 L/min; an high flow leads a greater stability of blood pressure during respiratory cycle and a decreasein WOB.

Initial PEEP- 5-6 cm of H2O. Thereafter, the CPAP level has to be adapted according to clinical condition,oxygenation, and perfusion.

Consensus with limited trial data Wean to $<0.30$ be-fore weaning PEEP

If $\mathrm{FiO}_{2}$ consistently $>0.40$

If consistently increased WOB If excessive or severeapnea

Table 1: Initial CPAP settings

\section{Non-invasive Positive pressure Ventilation}

Non-invasive intermittent positive pressure ventilation has emerged as an alternative strategy to n-CPAP. It delivers time-cycled positive pressure ven- tilation above a PEEP level in the absence of ET tube [16].

NIPPV can be delivered as:

\section{CMV NIPPV}

2. BiPAP (Bilevel - NIPPV)

CMV-NIPPV: CMV-NIPPV uses a ventilator to provide intermittent breaths at PIP and rates similar to those used for Mechanical Ventilation.

Physiological Principle:

1. Stablises the alveoli by providing positive airway pressure(PEEP)

2. Promotes better ventilation by delivering positive pressure breaths tothe lower airway

3. Triggers an augmented inspiratory reflex (head's paradoxical reflex) inpreterm infants.

4. Less inflammation than Invasive Mechanical Ventilation BiPAP:

It is a form of non-invasive ventilation that provides two alternating levels of CPAP at set intervals using nasal prongs or face mask while the baby is breathing spontaneously. Difference between high and low nCPAP pres- sure is $<4 \mathrm{~cm} \mathrm{H2O}$. BiPAP is an alternative method to increase mean airway pressure (MAP) without reaching peak values typical of CMV-NIPPV.
Physiological Principle:

1. Delta $\mathrm{P}$ produced by the ventilator creates a switch from FRC level toanother one

2. Derived changes in FRC improves alveolar ventilation

3. Vt depends on both Delta $\mathrm{P}$ and lung compliance.

CMV-NIPPV and BiPAP are respiratory support modality with different mechanism to support breathing and their use should be assessed on mer-its and clinical judgement in the same way as for other modalities of ventila-tion.

CMV-NIPPV and BiPAP can be delivered either synchronised or non-syn- chronised. There are various ways of synchronising breaths while the new- born is on CMV-NIPPV/BiPAP however, it is difficult to obtain synchronisa-tion due to open ventilation and very low pressure in preterm infants. NAVA presently offers better possibility of synchronisation. Oesophageal feedingtube is used for NAVA. It signals the onset of diaphragmatic contractions. However, in preterm the combination of diaphragmatic contractions/glottis opening is out of phase in $60 \%$ cases because glottis opening doesnot fol- low immediately diaphragm contraction. Therefore, ventilation flow could find the glottis closed although diaphragm starts to move downward.There- fore, synchronisation of breaths is difficult with CMV-NIPPV or BiPAP and hence both are generally used in a non-synchronised mode.

When compared with nCPAP; CNV-NIPPV/BiPAP improves thoraco-abdom- inal synchrony, increases tidal volume and minute ventilation and thus de-creases work of breathing and improves $\mathrm{CO} 2$ clearance. These effects are better pronounced with synchronised than non-synchronised ventilation.

\begin{tabular}{|c|c|}
\hline CMV-NIPPV & BiPAP \\
\hline Time cycled & Time cycled \\
\hline Spontaneously breathing neonate & Spontaneously breathing neonate \\
\hline $\begin{array}{l}\text { Uses PIP and PEEP similar to } \\
\text { Mechanical Ventilation }\end{array}$ & $\begin{array}{l}\text { Provides } 2 \text { alternating levels of CPAP at set interval } \\
\text { Higher CPAP pressure provided for sigh breaths is } \\
\text { much lower than PIP provided in CMV-NIPPV }\end{array}$ \\
\hline Shorter inflation time & $\begin{array}{l}\text { Longer inflation time }(0.5-1 \mathrm{sec}) \text { for the higher } \mathrm{nC}- \\
\text { PAP pressure }\end{array}$ \\
\hline
\end{tabular}




\section{Higher cycle rate(10-60/min)}

Indications for NIPPV [17]:

1. Post-extubation failure: In comparison with n-CPAP, NIPPV decreases thefrequency of post extubation failure; based on clinical judgement can be considered in neonates with CPAP failure.

2. Apnea of prematurity: In preterm with recurrent apneas while on CPAP,NIPPV has shown to reduce frequency of apnea or need for intubation.
Lower cycle rate(10-30/min)

There are 3 kind of interfaces applicable for NIPPV between device and newborn.

1. Short binasal prongs

2. Hypopharangeal tube

3. Nasal mask

Short binasal prongs represent the better interface for both the comfort of the neonate (they adapt correctly and with minimal injury) and the successof the technique (lower flow resistance).

\begin{tabular}{|c|c|}
\hline Variables & Suggested Initial Parameters \\
\hline PIP & $\begin{array}{c}10 \mathrm{~cm} \text { of } \mathrm{H} 2 \mathrm{O} \text { above CPAP or } 2 \mathrm{~cm} \text { of } \mathrm{H} 2 \mathrm{O} \\
\text { abovethe set PIP which was earlier applied } \\
\text { during Me- chanical Ventilation } \\
\text { Maximum PIP- } 22 \mathrm{~cm} \text { of } \mathrm{H} 2 \mathrm{O}\end{array}$ \\
\hline PEEP & $4-6 \mathrm{~cm}$ of $\mathrm{H} 2 \mathrm{O}$ \\
\hline Ventilation rate & $40-50 / \mathrm{min}$ \\
\hline FiO2 & Aim for SPO2 between $91-94 \%$ \\
MaximumFiO2-60\% \\
\hline Flow rate
\end{tabular}

Table 1: Initial Settings for CMV-NIPPV

\begin{tabular}{|c|c|}
\hline Variables & Suggested Initial Parameters \\
\hline Level of lower airway pressure & $4-6 \mathrm{~cm}$ of H2O \\
\hline Level of higher airway pressure & $8-10 \mathrm{~cm}$ of H2O \\
\hline Time of higher airway pressure \\
breaths
\end{tabular}

Table 2: Initial Settings for BiPAP

\section{Safety of NIPPV:}

1. Abdominal distension: Less likely to be clinically significant if regularOG tube aspiration is done.

2. Nasal septum erosion/nasal trauma similar to that observed with nCPAP

3. Air leak Syndrome

NIPPV Failure

Consider invasive ventilation in neonates on NIPPV with:

1. Worsening respiratory acidosis
2. Cardiorespiratory compromise

3. $\mathrm{FiO} 2$ requirement $>60 \%$.

\section{References}

1. Jobe AH, Bancalari E. (2001) Bronchopulmonary dysplasia. Am J Respir Crit Care Med. 163:1723-1729.

2. Álvarez-Fuente M, Arruza L, Muro M, et al. (2017) The economic impact of pre-maturity and bronchopulmonary dysplasia. Eur J Pediatr. 176: 1587-1593. 
3. Jensen EA, Schmidt B. (2014) Epidemiology of bronchopulmonary dysplasia. Birth Defects Res Part A Clin Mol Teratol. 100: 145-157.

4. Morley CJ, Davis PG, Doyle LW, Brion LP, Hascoet JM, Carlin JB. (2008) Nasal CPAP or intubation at birth for very preterm infants. N Engl J Med. 358: 700-708.

5. Finer NN, Carlo WA, Walsh MC, et al. (2010) Early CPAP versus surfactant in ex- tremely preterm infants. N Engl J Med. 362: 1970-1979.

6. Wilkinson D, Andersen C, O'Donnell C. (2007) High flow nasal cannula for respi- ratory support in preterm infants (Protocol). Cochrane Database Syst Rev.

7. Walsh M, Engle W, Laptook A, KazziSN, Buchter S, Rasmussen M, et al. (2005) Oxygen delivery through nasal cannulae to preterm infants: can practice be improved? Pediatrics. 116(4):857-861.

8. Dysart K, Miller TL, Wolfson MR, Shaffer TH. (2009) Research in high flow thera- py: mechanisms of action. Respir Med. 103: 1400-1405.

9. Shoemaker MT, Pierce MR, Yoder BA, Digeronimo RJ. (2007) High flow nasal cannula versus nasal CPAP for neo-natal respiratory disease: a retrospective study. J Perinatol. 27(2):8591.

10. Sreenan C, Lemke RP, Hudson-Mason A, Osiovich H. (2001) High-flow nasal cannulae in the management of apnea of prematurity: a comparison with conventional nasal continuous positive airway pressure. Pediatrics. 107(5):1081-1083.
11. Kubicka ZJ, Limauro J, Darnall RA. (2008) Heated, humidified high-flow nasal cannula therapy: yet another way to deliver continuous positive airway pressure? Pediatrics. 121(1):82-88.

12. Ho JJ, Subramaniam P, Henderson-Smart DJ, Davis PG. (2002) Continuous dis- tending pressure for respiratory distress syndrome in preterm infants. Cochrane Database of Systematic Reviews.

13. Dani C, Bresci C, Lista G, Martano C, Messina F, Migliori C, et al. (2013) Neona- tal respiratory support strategies in the Intensive Care Unit: An Italian sur- vey. Eur J Pediatr. 172:331-336.

14. Thomas MA on behalf of the IFDAS Study Group. (2002) Early nasal continuous positive airways pressure (nCPAP) with prophylactic surfactant for neonates at risk for RDS. The IFDAS multi- centre randomised trial. Archives of Dis-ease in Childhood.

15. Robertson NJ, Hamilton PA, Moss AL. (1996) Nasal deformities resulting from flow driver continuous positive airway pressure. Arch Dis Child Fetal Neona- tal Ed. 73(3):209212.

16. Bhandari V. (2010) Nasal intermittent positive pressure ventilation in the new-born: Review of literature and evidence-based guidelines. J Perinatol. 30:505-512.

17. Moretti C, Gizzi C, Montecchia F, Barbàra CS, Midulla F, Sanchez-Luna M,et al. (2016) Synchronized Nasal Intermittent Positive Pressure Ventilation of the Newborn: Technical issues and clinical results. Neonatology. 109:359-365. 